\title{
Efficacy of Over-the-Counter (OTC) Medical Device Products as a Tool in Clinical Weight Management
}

\author{
William Michael Froese ${ }^{1 *}$, Mark Elliott Ludlow ${ }^{2 \#}$ \\ ${ }^{1}$ Business and Technology Division, College of Lake County, Grayslake, USA \\ ${ }^{2}$ Consulting Engineer, Astoria, USA \\ Email: wfroese@clcillinois.edu, mark@ludlow.com
}

Received 23 June 2014; revised 27 July 2014; accepted 6 August 2014

Copyright (C) 2014 by authors and Scientific Research Publishing Inc.

This work is licensed under the Creative Commons Attribution International License (CC BY). http://creativecommons.org/licenses/by/4.0/

\section{(c) (i) Open Access}

\section{Abstract}

Background: Obesity is a significant public health challenge. Its prevalence is increasing at an alarming rate globally. Numerous slimming products crowd the market, with each offering a proprietary formulation with statements of alleged efficacy. Within the EU, one such class is Medical Device, featuring a range of marine- and vegetal-based fibers as the functional ingredient. Methods: An analysis was performed to investigate and compare the lipid binding performance of three medical devices consisting of: 1) a polyglucosamine; 2) a vegetal opuntia extract; and 3) a vegetal opuntia extract with vitamins using an industry-standard, validated test method. 0.5 gr of material from each product was studied. Results: The polyglucosamine exhibited a lipid binding capacity $(691.7 \mathrm{~g} / \mathrm{g})$ more than 20 times the vegetal opuntia extracts. A significantly higher standard deviation $( \pm 12.1)$ was reported for the polyglucosamine medical device vs. the vegetal opuntia extracts $( \pm 1.3-4.8)$. However, the standard deviation reported for the former is approximately $1.7 \%$ of the mean value obtained from double determination, significantly smaller than that $2.5 \%-15 \%$ observed for the extracts. Conclusions: Analysis of lipid binding indicated the polyglucosamine exhibited a substantially higher capacity than the vegetal opuntia samples. Further studies are needed to validate these in vitro results.

\section{Keywords}

Obesity, Weight Management, Lipid Binding, Chitosan, Medical Device

\footnotetext{
${ }^{*}$ Corresponding author.

"B.S.M.E., P.E.

How to cite this paper: Froese, W.M. and Ludlow, M.E. (2014) Efficacy of Over-the-Counter (OTC) Medical Device Products as a Tool in Clinical Weight Management. Food and Nutrition Sciences, 5, 1637-1643. 


\section{Introduction}

According to the Centers for Disease Control, the past 20 years has seen a dramatic increase in obesity, not only in the US but worldwide. More than one-in-three US adults (35.7\%) and nearly one-in-five children and adolescents under the age of 19 (17\%) are obese [1].

Globally, the number is even more staggering. Medscape’s 2013 Global Burden of Disease Study reported between 1980 and 2013 that the combined prevalence of overweight and obesity worldwide rose from 857 million in 1980 to 2.1 billion, $27.5 \%$ in adults and $47.1 \%$ in children [2].

And it's big business.

Market data estimate that the total US weight loss market grew to \$61.6 billion in 2012, the last year of reported data.

Over the Counter (OTC) dietary supplements to treat obesity appeal to many patients who desire a "magic bullet” for weight loss. A 2004 analysis by Saper [3] identified more than 50 individual dietary supplements and more than 125 commercial combinations are available for weight loss.

Notable was the move to do-it-yourself weight management programs as dieters shifted toward greater use of free and low-cost, do-it-yourself diet plans (diet websites, OTC supplements, meal replacements and diet books). Market data find that the share of dieters who prefer a self-directed program now exceeds $82 \%$. Historically since 1989 , about $70 \%$ of dieters have used a self-directed plan [4].

Use of non-prescription weight loss supplement use appears to be common among many segments of the US adult population. According to a study in the Journal American Diabetic Association, an estimated 15.2\% of adults have used a weight-loss supplement and 8.7\% have used within the last 12 months [5].

Despite long-term use, most patients do not discuss this practice with their care giver, let alone disclose specifics regarding nutraceutical product(s) used, active ingredient(s) or level of self-dosing. As a health care provider, you are in an ideal position to talk to your patients about weight control and to set the record straight as to specific supplement efficacy and safety as part of their overall "energy balance care”, balancing supplementation with diet, nutrition, exercise, and health education. However, due to the plethora of available OTC products, the challenge is a familiarity with active ingredient(s), in addition to brand safety and efficacy data. Qualified professionals should inquire about their patients' use of supplements for weight loss in order to facilitate discussion about the presence or lack of efficacy data, possible adverse effects, as well as to dispel misinformation that may interfere with sound weight-management practices.

\subsection{Chitosan: A Polysaccharide-Derived Fiber}

There are numerous nutraceutical products to consider incorporating into a weight management program. Among soluble fibers, one such polysaccharide is chitosan.

Chitosan, a shellfish-based soluble fiber, has been the subject of ongoing, intense scientific research because of its unique physical properties that can be used to affect a variety of systems.

Structurally, this unique compound is actually a polymer of glucosamine and N-acetylglucosamine, the most abundant polymer after cellulose.

Chitosan is derived from chitin, typically obtained from the shells of crustaceans including crab, lobster and shrimp. However, chitosan can also be derived from fungal chitins.

Chitosan's chemical structure is best described as a polyglucosamine. During a process called deacetylation, (a process that chemically removing the acetyl group from the $\mathrm{N}$-acetylglucosamine), a positively charged amine group can be formed at pH's below 6.5, giving this polymer some of its unique and versatile functions. It is the only known positively charged dietary fiber. As shown in Figure 1, this structure is a $\beta$ - $(1,4)$ linked polymer of D-glucosamine, which does not get broken down by human gastrointestinal enzymes.

Recommended by wholistic practitioners to lower cholesterol, chitosan has also been promoted as a type of dietary fiber that may help reduce the absorption of fat due to its ability to "bind" fat and bile salts in the human gastrointestinal tract and pass this complexed fat-chitosan mixture out the body. This action reduces absorbed fat, and has prompted scientists to investigate the ability of chitosan to help with weight loss [6]-[11].

Chitosan is currently approved as both a food additive, a dietary supplement, and, in many countries, as a medical device. The latter provides stronger evidence as to the compound's safety and efficacy. However, despite its efficacy and safety, this unique fiber has been criticized by various health and governmental ministries and even some well-intentioned nutritionists. In most instances, these have resulted from unscrupulous suppliers 


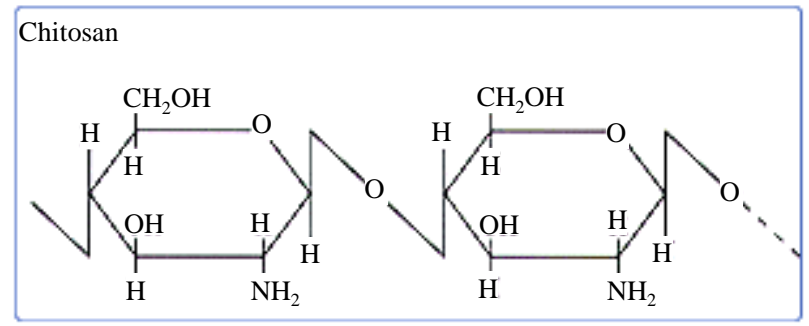

Figure 1. Molecular structure of chitosan.

promoting unrealistic performance claims on lipid absorption (fat binding) unsubstantiated with laboratory or clinical data. In other areas, nutrition concerns over chitosan's potential to decrease the absorption of fat-soluble vitamins have caused health ministries to ban its use. Finally, several of the existing clinical studies cited as scientific proof of chitosan's inability to effect weight loss can best be summarized as junk science as they have not followed the traditionally accepted standard of scientific investigation-a double-blind, placebo controlled design where dietary intake is carefully monitored and controlled. Given the lack of practitioner knowledge, in the area of polyglucosamines and weight management, a perpetuation of negative reports has been circulating in the popular press.

The hypocholesterolemic and lipid lowering effects of chitosan are well recognized but the specific mechanisms are not fully understood.

The three prevailing hypotheses are:

- Ionic interaction: Chitosan's strong, positive charged amino group might bind to the negatively charged bile acids [12]-[15] which, when excreted, would lead to conversion of cholesterol to bile acids in the liver in order to compensate for the fecal losses and, thus, would account for the observed cholesterol-lowering effects. However, this mechanism does not explain the increased loss of neutral fats such as cholesterol.

- Entrapment of mixed micelles, bile acids and fatty acids or triglycerides: In the small intestine, chitosan forms an expanded gel-like structure. Intestinal micelles (tiny fat globules where a core of fatty acids and cholesterol are surrounded by water-soluble bile salts) may be entrapped by absorbing onto the chitosan matrix [10] [16] [17] or disrupted by chitosan's presence, thus diminishing normal fat absorption.

- Competitive inhibitor of pancreatic lipase: As a co-inhibitor of this enzyme responsible for fatty acid cleavage, the amount of fat digested and absorbed would be decreased [18].

However, some research has suggested that ionic binding alone may not provide sufficient explanation for the observed effects nor would it explain the "binding" of uncharged fat molecules, such as cholesterol or triglycerides. Scientists think the larger chitosan polymer may envelop or entrap the fatty compounds (micelles) and prevent them from being emulsified and digested [19]-[22].

Overall, the mechanisms involved in chitosan's binding of dietary fat involve a combination of the above stated mechanisms, but none specifically have been confirmed.

\subsection{In Vitro and in Vivo Efficacy}

Investigators have demonstrated by both in vitro (laboratory) and in vivo (in animals and man) studies that chitosan does bind dietary fat and prevents its absorption from the gut [13] [16] [23] [24]. In a study testing 23 different dietary fibers, chitosan was shown to markedly increase the fecal lipid excretion and reduce the apparent fat digestibility to about half compared to the control diet (cellulose) and was significantly more effective than the other fibers [25]. In addition, the ability to reduce plasma cholesterol via decreasing bile acid reabsorption is better than that seen with other dietary soluble fibers, such as psyllium or guar and is far greater than cholestyramine, a synthetic bile acid sequestrant [17]. What seems to vary is how much fat binds to each gram of chitosan. These parameters may be affected by such factors as chitosan type (viscosity, molecular weight, particle size, etc.), blending of chitosan with other agents, and, naturally in humans, human variability.

\subsection{Human Studies Indicate Positive Effect on Weight Loss}

Numerous studies have shown chitosan can be an effective tool to help with weight control. Several of the more recognized studies include: 
- Sciutto [9] and Colombo [26]: Two separate studies showed substantial weight loss in groups consuming chitosan. In one, 90 obese subjects were randomly assigned to a low-calorie diet plus chitosan. The dietplus-chitosan group lost statistically more body weight than the placebo group (15.9 lbs vs $8.0 \mathrm{lbs}$ ).

- Giustina [11]: This 4-week study reported significantly greater weight loss when consuming chitosan than the controls (16.1 lbs vs $6.6 \mathrm{lbs})$.

- Veneroni [10]: In a trial of 100 subjects, the chitosan group lost 18.3 lbs compared to the placebo group of $6.6 \mathrm{lbs}$.

- Macchi [27] and Columbo [26]: Reported similar body weight changes as in the Sciutto, Giustina and Veneroni studies.

- Abelin [28]: Significant weight and blood pressure reduction occurred in moderately obese subjects with the chitosan group losing almost 10 pounds more than the placebo group.

- MATS Medical AB [28]: Indicated subjects lost 15 lbs in four weeks vs placebo group (5 lbs).

- Ernst [29]: Finally, the meta-analysis of six Italian studies indicated that, overall, chitosan groups showed significantly greater weight loss than placebo groups with a mean difference in weight of 6.2 lbs.

\section{Purpose}

Although significant study indicates the role of chitosan as a weight management adjunct to diet and exercise, few researchers extend their analyses beyond the raw ingredient to analyze the efficacy and safety of chitosan once incorporated into a finished, OTC retail product.

One recent study conducted by the Seafood Research and Education Center, Oregon State University, compared lipid binding capability of three OTC medical device slimming products using an industry-accepted lipid binding protocol independently validated in both Europe, North America and Asia [30] [31].

\section{Materials and Methods}

Three commercially-available medical device samples were used:

- A marine-based polyglucosamine (Formoline Lot \#AA20504) was purchased at retail in Germany;

- A vegetal-based opuntia extract (XLS Medical Lot \#2114) was purchased at retail in Portugal;

- A vegetal-based opuntia extract with vitamins (Liposinol Lot \#1118) was purchased at retail in Switzerland.

Data regarding degree of deacetylation, molecular weight or viscosity were unavailable. The extra virgin olive oil used was purchased at retail in America. All remaining reagents and solvents used were of analytical reagent grade. All materials were used as received.

Analysis was performed by the Oregon State University, Seafood Research and Education Center, using the industry-accepted in vitro lipid binding test procedure [30], and independently validated in Europe, North America and Asia [31].

\section{Results and Discussion}

Lipid binding capacity (g/g) of the three samples is presented in Figure 2. The lipid binding capacity (691.7 g/g) of the polyglucosamine sample was reported to be more than 22 times the binding capacity of both the vegetal opuntia extract and the vegetal opuntia extra with vitamins samples, $31.2 \mathrm{~g} / \mathrm{g}$ and $51.9 \mathrm{~g} / \mathrm{g}$, respectively. All results are means of two determinations \pm standard deviation.

Neither of the three samples completely dissolved in $60 \mathrm{~mL}$ of $0.16 \mathrm{~N} \mathrm{HCl}$ after 60 minutes of stirring at room temperature. It would appear that certain ingredients in all three samples cannot be dissolved in $0.16 \mathrm{~N} \mathrm{HCl}$, possibly due to the excipients used in the manufacture of each sample's final tablet form. Analysis of the solubility of each component in the three samples in the weak acidic solution is recommended to further identify which ingredient(s) in the product is (are) not dissolvable in the acidic solution.

The lipid binding capacity $(691.7 \mathrm{~g} / \mathrm{g})$ of the polyglucosamine sample was reported as 22.17 times greater than that $(31.2 \mathrm{~g} / \mathrm{g})$ of the opuntia extract and 13.33 times greater than that $(51.9 \mathrm{~g} / \mathrm{g})$ of the opuntia extract with vitamins.

Since neither of the three samples completely dissolved in $60 \mathrm{~mL}$ of $0.16 \mathrm{~N} \mathrm{HCl}$ after 60 minutes of stirring at room temperature, it is hypothesized that one or more of the excipients used in the manufacture of the finished tablet form diminished dissolution performance. 


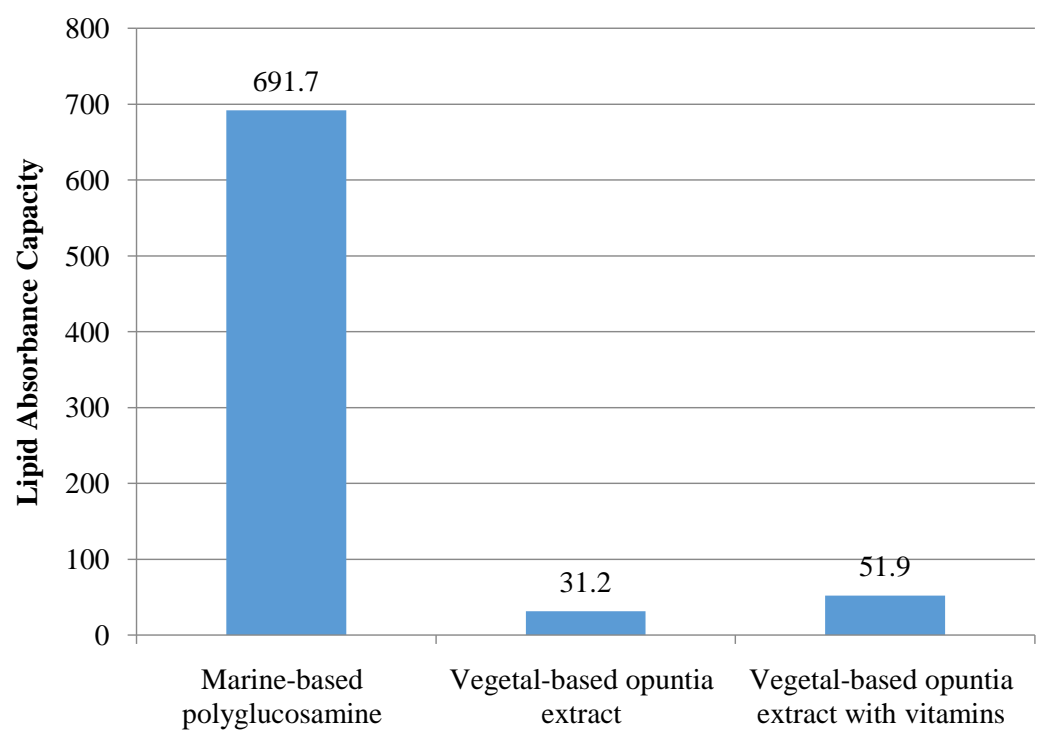

Figure 2. Lipid binding capacity (g/g polyglucosamine).

Significantly lower lipid bindingcapacity was observed for both of the biopolymers of vegetal origin compared to the marine-based biopolymer. It is hypothesized that this may be the result of variations in the molecular structure found in marine vs. vegetal biopolymers.

The authors note that both of these hypotheses require further investigation.

A significantly higher standard deviation (12.1) was reported for the polyglucosamine sample than reported for either of the two-vegetal-based opuntia extracts samples, 4.8 and 1.3, respectively. However, the standard deviation reported for the polyglucosamine is $1.7 \%$ of the mean value obtained from double determination, which is significantly smaller than that $15.4 \%$ observed for the opuntia extract and less than the $2.5 \%$ for the opuntia extract with vitamins sample.

Unreported are additional factors, including the skill of the technician, batch of olive oil used in testing, variability of the biopolymers used in each sample, excipient variability between samples, and batch variability that may affect the lipid binding capacity of each product. The small standard deviation ( $1.7 \%$ of the mean value) reported for the polyglucosamine sample indicates product uniformity as well as good personal skills in performing the test. It is not clear what other factors contributed to the large standard deviation, up to $15 \%$, observed for the other samples. It is speculated that certain active ingredients in both vegetal opuntia extracts might interfere with the lipid binding interaction between the respective biopolymers and olive oil, which would then contribute to low lipid binding capacity of the product. However, such a speculation remains to be investigated.

\section{Summary}

Analysis of lipid binding capacity of three biopolymers - a polyglucosamine, a vegetal opuntia extract and a vegetal opuntia extract with vitamins - indicated that the polyglucosamine exhibited a significantly higher lipid binding capacity $(691.7 \mathrm{~g} / \mathrm{g}$ ) than was reported for either of the two opuntia samples, $31.2 \mathrm{~g} / \mathrm{g}$ and $51.9 \mathrm{~g} / \mathrm{g}$, respectively.

Many factors, including technician skill, the class of biopolymer and its respective molecular structure, variability between samples, and batch variability could affect results obtained from lipid binding analysis. The much lower lipid binding capacity observed for the two vegetal opuntia-derived samples may be the result in a variation in the raw active ingredient or interference in lipid binding capacity between the active ingredients and other non-active (excipient) ingredients. Analysis of lipid binding capacity of each of the non-active ingredients in all samples might provide answers to the speculation.

So, regardless of how effective a fat binder L112 chitosan is, it is not the universal weight loss aid for all people. However, as the initial analysis has indicated, L112 chitosan can help by decreasing the amount of kcal we get by inhibiting some dietary fat absorption. This is because fat provides approximately 9 kcal for every 
gram of fat eaten, and carbohydrates provide only 4 kcal per gram of carbohydrate eaten; so, when you consume chitosan, it binds to the fat and both get expelled from the body. Thus, chitosan can decrease intake of calories from fat. When daily calorie levels are decreased (3500 kcal equals one pound of body fat), weight loss can occur.

Despite the success of determining initial rankings of lipid binding performance of L112 polyglucosamine vs. XLS and Liposinol vegetal extracts, the analysis indicates the need for ongoing study across a more diverse range of OTC soluble fiber products to better inform the health care provider as to the efficacy and safety of these adjuncts to a weight management and exercise program.

\section{Acknowledgements}

The authors wish to express their thanks to the Seafood Research and Education Center, Oregon State University, (Astoria, OR) for their assistance in the methodology and laboratory analysis.

\section{References}

[1] Centers for Disease Control and Prevention (2014) Overweight and Obesity: Adult Obesity Facts. http://www.cdc.gov/obesity/data/adult.html

[2] Medscape (2013) Global Burden of Disease. http://www.medscape.com/viewarticle/825858

[3] Safer, R.B. and Phillips, R.S. (2004) Common Dietary Supplements for Weight Loss. American Family Physician, 70, 9.

[4] PRWeb (2012) US Weight Loss Market Forecast to Hit \$66 Billion in 2013. http://www.prweb.com/releases/2012/12/prweb10278281.htm

[5] Blanck, H.M., Serdula, M.K., Gillespie, C., Galuska, D.A., Sharpe, P.A., Conway, J.M., Khan, L.K. and Ainsworth, B.E. (2007) Use of Nonprescription Dietary Supplements for Weight Loss Is Common among Americans. Journal of the American Dietetic Association, 107, 441-447.

[6] Pittler, M.H., Abbot, N.C., Harkness, E.F. and Ernst, E. (1999) Randomized, Double-Blind Trial of Chitosan for Body Weight Reduction. European Journal of Clinical Nutrition, 53, 379-381. http://dx.doi.org/10.1038/sj.ejcn.1600733

[7] Han, L.K., Kimura, Y. and Okuda, H. (1999) Reduction in Fat Storage during Chitin-Chitosan Treatment in Mice Fed a High-Fat Diet. International Journal of Obesity and Related Metabolic Disorders, 123, 174-179. http://dx.doi.org/10.1038/sj.ijo.0800806

[8] Macchi, G. (1996) A New Approach to the Treatment of Obesity: Chitosan's Effects on Body Weight Reduction and Plasma Cholesterol Levels. Acta Toxicol Ther, 17, 303-320.

[9] Sciutto, A.M. and Colombo, P. (1995) Lipid-Lowering Effect of Chitosan Dietary Integrator and Hypocaloric Diet in Obese Subjects. Acta Toxicol Ther, 16, 215-229.

[10] Veneroni, G., Veneroni, F., Contos, S., et al. (1996) Effect of a New Chitosan on Hyperlipidemia and Overweight in Obese Patients. Chitin Enzymology, 2, 55-62.

[11] Giustina, A. and Ventura, P. (1995) Weight-Reducing Regimens in Obese Subjects: Effects of a New Dietary Fibre Integrator. Acta Toxicologica et Therapeutica, 16, 199-214.

[12] Sugano, M., Fujikawa, T., Hiratsuji, Y. and Hasegawa, Y. (1978) Hypocholesterolemic Effects of Chitosan in CholesterolFed Rats. Nutrition Reports International, 18, 531-537.

[13] Sugano, M., Fujikawa, T., Hiratsuji, Y., et al. (1980) A Novel Use of Chitosan as a Hypocholesterolemic Agent in Rats. The American Journal of Clinical Nutrition, 33, 787-793.

[14] Nagyvary, J.J., Falk, J.D., Hill, M.L., et al. (1979) The Hypolipidemic Activity of Chitosan and Other Polysaccharides in Rats. Nutrition Reports International, 20, 677-684.

[15] Kobayashi, T., Otsuka, S. and Yugari, Y. (1979) Effect of Chitosan on Serum and Liver Cholesterol in Cholesterol-Fed Rats. Nutrition Reports International, 19, 327-334.

[16] Furda, I. (1983) Aminopolysaccharides-Their Potential as Dietary Fiber. In: Furda, I., Ed., Unconventional Sources of Dietary Fiber, ACS Symposium Series, General Mills, Inc., Minneapolis, 105-122.

[17] Nauss, J.L., Thompson, J.L. and Nagyvary, J.J. (1983) The Binding of Micellar Lipids to Chitosan. Lipids, 18, 714-719. http://dx.doi.org/10.1007/BF02534538

[18] Han, L.K., Kimura, Y. and Okuda, H. (1999) Reduction in Fat Storage during Chitin-Chitosan Treatment in Mice Fed a High-Fat Diet. International Journal of Obesity and Related Metabolic Disorders, 123, 174-179. http://dx.doi.org/10.1038/sj.ijo.0800806 
[19] Sugano, M., Watanabe, S., Kishi, A., et al. (1988) Hypocholesterolemic Action of Chitosans with Different Viscosity in Rats. Lipids, 23, 187-191. http://dx.doi.org/10.1007/BF02535456

[20] Sugano, M., Yoshida, K., Hashimoto, M., et al. (1992) Hypocholesterolemic Activity of Partially Hydrolyzed Chitosans in Rats. In: Brine, C.J., Sanford, P.A. and Zikakis, J.P., Eds., Advances in Chitin and Chitosan, Elsevier Applied Science, London, 472-478. http://dx.doi.org/10.1007/978-94-011-5942-5 53

[21] Ikeda, I., Sugano, M., Yoshida, K., et al. (1993) Effects of Chitosan Hydrolysates on Lipid Absorption and on Serum and Liver Lipid Concentrations in Rats. Journal of Agricultural and Food Chemistry, 41, 431-435. http://dx.doi.org/10.1021/jf00027a016

[22] Furda, I. (2000) Reduction of Absorption of Dietary Lipids and Cholesterol by Chitosan and Its Derivatives and Special Formulations. In: Muzzareilli, R.A.A., Ed., Chitosan per os: From Dietary Supplement to Drug Carrier, RAA Muzzareilli, Ed., Atec, Grottammare.

[23] Vahouny, G.V., Satchithanandam, S., Cassidy, M.M., et al. (1983) Comparative Effect of Chitosan and Cholestyramine on Lymphatic Absorption of Lipids in the Rat. The American Journal of Clinical Nutrition, 38, 278-284.

[24] Kanauchi, O., Deuchi, K., Imasato, Y., et al. (1995) Mechanism for the Inhibition of Fat Digestion by Chitosan and for the Synergistic Effect of Ascorbate. Bioscience, Biotechnology, and Biochemistry, 59, 786-790. http://dx.doi.org/10.1271/bbb.59.786

[25] Deuchi, K., Kanauchi, O., Imasato, Y. and Kobayashi, E. (1994) Decreasing Effect of Chitosan on the Apparent Digestibility by Rats Fed on a High-Fat Diet. Bioscience, Biotechnology, and Biochemistry, 58, 1613-1616. http://dx.doi.org/10.1271/bbb.58.1613

[26] Colombo, P. and Sciutto, A.M. (1996) Nutritional Aspects of Chitosan Employment in Hypocaloric Diet. Acta Toxicologica et Therapeutica, 17, 287-302.

[27] Macchi, G. (1996) A New Approach to the Treatment of Obesity: Chitosan's Effects on Body Weight Reduction and Plasma Cholesterol Levels. Acta Toxicologica et Therapeutica, 17, 303-320.

[28] Abelin, J. and Rossner, S. (1995) Fat Binder, a Study of Safety in Obese Patients. MATS Medical AB, Stockholm.

[29] Ernst, E. and Pittler, M.H. (1998) Chitosan as a Treatment for Body Weight Reduction: A Meta-Analysis. Perfusion, 11, 461-465.

[30] Certmedica International GmbH (2011) Test Procedure: Certmedica in Vitro Test to Determine the Fat Binding Capacity of Polymers. Certmedica International GmbH, Aschaffenburg.

[31] Bigalke, J. (2011) Certmedica in Vitro Test zur Bestimmung des FettbindevermÖgens von Biopolymeren: Validierungsbericht Bestimmung des Fettbindevermögens von Biopolymeren. BigLab, Marburg. 
Scientific Research Publishing (SCIRP) is one of the largest Open Access journal publishers. It is currently publishing more than 200 open access, online, peer-reviewed journals covering a wide range of academic disciplines. SCIRP serves the worldwide academic communities and contributes to the progress and application of science with its publication.

Other selected journals from SCIRP are listed as below. Submit your manuscript to us via either submit@scirp.org or Online Submission Portal.
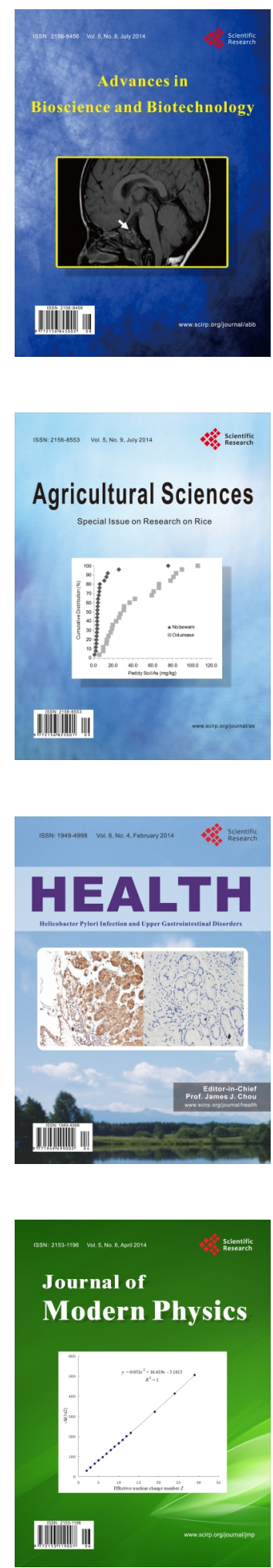
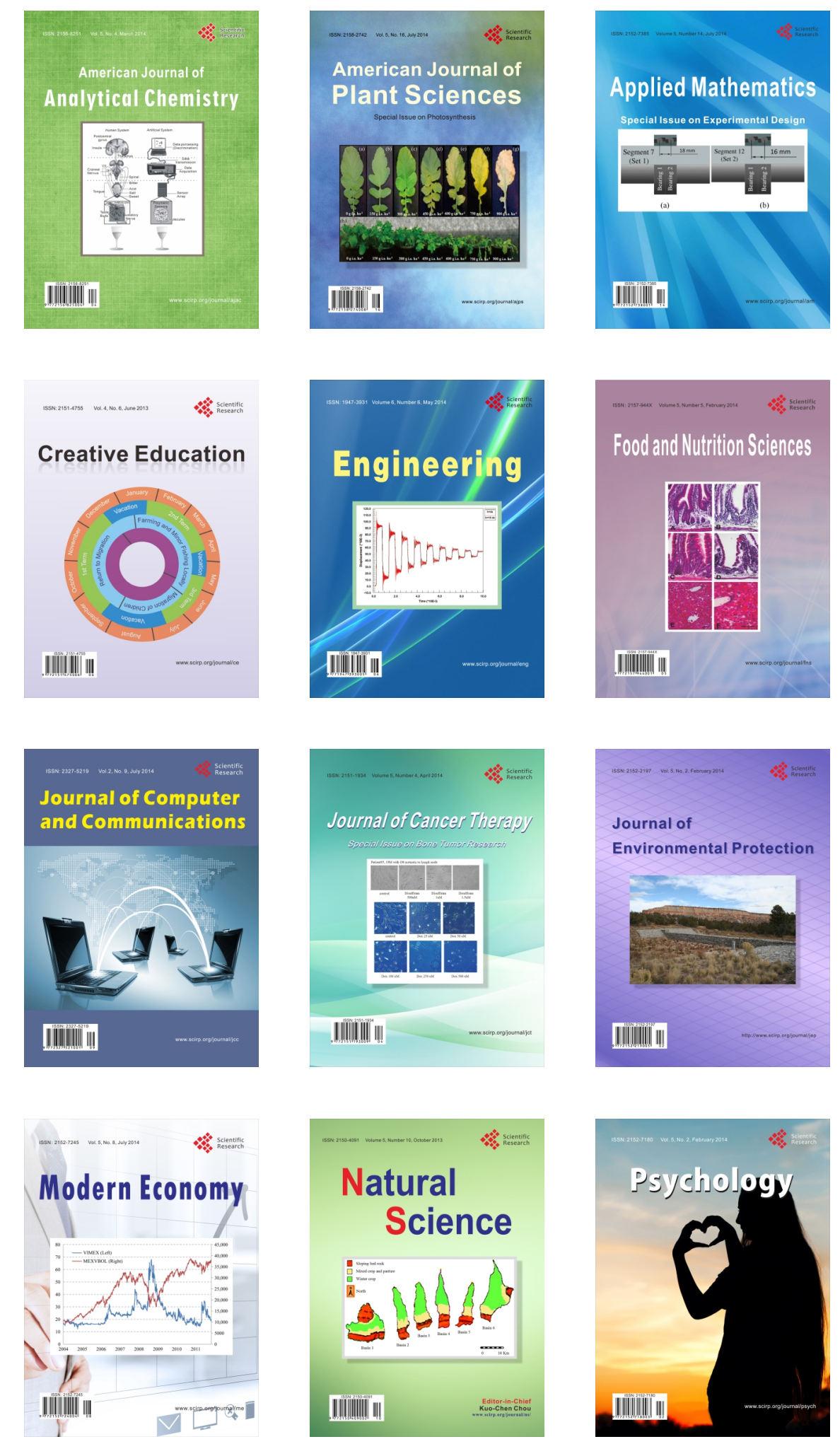